\title{
Pengaruh Kualitas Layanan dalam Menciptakan Kepuasan Publik di Kantor Pelayanan Publik, Jakarta Utara
}

\section{Effect of Service Quality in Creating Public Satisfaction at the Public Service Office, North Jakarta}

\author{
Janny Rowena $^{1}$, Fuji Rahayu Wilujeng ${ }^{2 *}$, Glisina Dwinoor Rembulan ${ }^{2}$ \\ ${ }^{1}$ Program Studi Manajemen, Universitas Bunda Mulia, Jl. Lodan Raya No. 2 Ancol, Jakarta Utara 14430, \\ Indonesia \\ ${ }^{2}$ Program Studi Teknik Industri, Universitas Bunda Mulia, Jl. Lodan Raya No. 2 Ancol, Jakarta Utara 14430, \\ Indonesia
}

Diterima: 15 Oktober, 2019 / Disetujui: 15 Januari, 2020

\begin{abstract}
One indicator that shows the quality of government performance is the quality of public service offices. Public services in Indonesia have an important role in economic and political life. The magnitude of the role of the district office in providing services around population bureaucracy issues, especially in the province of DKI Jakarta, is still often getting complaints from the public. This study aims to assess the level of community satisfaction with the quality of district office services in the Jakarta province, specifically the North Jakarta municipality. This study uses multilinear regression and uses the T-test to find out the significant level of influence of independent variables on the dependent. The study used five exogenous variables (procedures, information, time, facilities, and infrastructure, and environmental comfort) and 1 endogenous variable (satisfaction). The results of this study are all exogenous variables that have a positive and significant effect on the satisfaction of Jakarta citizens, which means that urban district office services have a positive and significant effect on the satisfaction of Jakarta citizens when viewed from procedures, information, time, facilities, and infrastructure as well as environmental comfort. The provincial government of DKI Jakarta must maintain and improve existing service procedures, some attributes of information that are already very good, good values regarding the certainty of the time of completion of services, several aspects of facilities and infrastructure, and comfortable environmental conditions, both in the service office or in the service support facilities.
\end{abstract}

Keywords: Government, Public services, Society satisfaction, District office

\begin{abstract}
ABSTRAK
Salah satu indikator yang memperlihatkan kualitas performa dari pemerintahan adalah kualitas kantor pelayanan publik. Pelayanan publik di Indonesia memiliki peran penting pada kehidupan ekonomi dan politik. Besarnya peran dari kantor kelurahan dalam memberikan pelayanan seputar permasalahan birokrasi kependudukan, khususnya di provinsi DKI Jakarta hingga saat ini masih sering mendapat keluhan dari masyarakat. Penelitian ini bertujuan untuk menilai tingkat kepuasan masyarakat atas kualitas pelayanan kantor kelurahan di provinsi Jakarta, khususnya kotamadya Jakarta Utara. Penelitian ini menggunakan multilinier regresi dan menggunakan uji T untuk mencari tahu tingkat signifikan dari pengaruh variabel independen terhadap dependen. Penelitian menggunakan lima variabel eksogen (prosedur, informasi, waktu, sarana dan prasarana, serta kenyamanan lingkungan) dan 1 variabel endogen (kepuasan). Hasil dari penelitian ini adalah seluruh variabel eksogen berpengaruh positif dan signifikan terhadap kepuasan warga Jakarta yang berarti pelayanan kantor kelurahan berpengaruh positif dan signifikan terhadap kepuasan warga DKI Jakarta jika dilihat dari prosedur, informasi, waktu, sarana dan prasarana juga kenyamanan lingkungan. Pemerintah provinsi DKI Jakarta harus mempertahankan dan meningkatkan prosedur pelayanan yang telah ada, beberapa atribut informasi yang sudah sangat baik, nilai-nilai yang baik mengenai kepastian waktu penyelesaian pelayanan, beberapa aspek sarana dan prasaran, dan kondisi lingkungan yang nyaman, baik itu di kantor pelayanan ataupun di fasilitas penunjang pelayanan.
\end{abstract}

Kata kunci: Pemerintahan, Pelayanan publik, Kepuasan masyarakat, Kantor kelurahan

*email: fwilujeng@bundamulia.ac.id 


\section{PENDAHULUAN}

\subsection{Latar Belakang}

Salah satu indikator yang memperlihatkan kualitas kinerja dari pemerintahan adalah kualitas kantor pelayanan publik. Pelayanan publik di Indonesia memiliki peran penting pada kehidupan ekonomi dan politik. Saat ini secara umum di Indonesia kualitas pelayanan publik masih kurang baik, dan hal ini tentu berdampak pada timbulnya krisis kepercayaan di masyarakat terhadap birokrasi publik (Sancoko, 2010). Hal ini menjadi sangat kontradiktif dengan begitu besarnya kepercayaan pemerintah pusat kepada daerah untuk mengatur rumah tangganya sendiri, melalui Undang-Undang Republik Indonesia Nomor 32 Tahun 2004, semestinya pemerintah daerah mampu menggunakan dan mengelola kepercayaan ini dengan sebaik-baiknya untuk fokus terhadap pelayanan kepada masyarakat. Berbagai isu di masyarakat bermunculan mengenai kualitas pelayanan yang diterima, bahwa pelayanan tersebut belumlah memenuhi harapan (Papadomichelaki dan Mentzas, 2011; Chatzoglou et al., 2013), padahal sebagai abdi masyarakat sebaiknya aparatur negara dapat memberikan pelayanan yang prima dan baiknya kualitas pelayanan akan berdampak pada besarnya kepercayaan publik terhadap kinerja pemerintah (Ramseook-Munhurrun, LukeaBhiwajee dan Naidoo, 2010; Yandri, 2013; Ningsih, 2015) Upaya untuk memperbaiki kualitas jasa tidak hanya berdampak positif bagi pelanggan namun dapat juga meningkatkan kepuasan kerja bagi karyawan (Rahayu, Rasid dan Tannady, 2018). Peran untuk mengubah organisasi tidak hanya datang dari tim manajemen namun juga harus datang dari karyawan (Rahayu, Rasid dan Tannady, 2019).

$$
\text { Di dalam Keputusan Menteri }
$$

Pendayagunaan Aparatur Negara

(KEPMENPAN) Nomor 63 Tahun 2003 tentang pedoman umum penyelenggaraan pelayanan publik menyebutkan bahwa pelayanan publik adalah segala kegiatan pelayanan yang dilaksanakan oleh penyelenggara pelayanan publik sebagai upaya pemenuhan kebutuhan penerima pelayanan maupun pelaksana ketentuan perundang-undangan. Salah satu unit pelayanan terhadap publik yang ada di daerah adalah kantor kelurahan. Kantor kelurahan merupakan unit pemerintahan yang bertugas melayani masyarakat pada tingkat kelurahan dan merupakan ujung tombak dari tingginya komitmen atas semangat untuk melayani masyarakat.

Selaras dengan perubahan lingkungan bisnis dan teknologi yang begitu cepat, organisasi juga dituntut untuk melakukan perubahan ke arah yang lebih baik (Tannady, Erlyana dan Nurprihatin, 2019; Tannady, Ismuhadjar dan Zami, 2019) Tim manajemen perlu menyadari bahwa perkembangan bisnis terus berubah dan tidak tetap sehingga perlu adanya upaya perbaikan berkesinambungan (Tannady dan Sitorus, 2017). Besarnya peran dari kantor kelurahan dalam memberikan pelayanan seputar permasalahan birokrasi kependudukan, khususnya di provinsi DKI Jakarta hingga saat ini masih sering mendapat keluhan dari masyarakat. Melalui portal lapor.go.id dapat diidentifikasi sejumlah keluhan terhadap kantor kelurahan yang ada di DKI Jakarta. Pada situs www.lapor.go.id terdapat keluhan warga mengenai pelayanan di kelurahan Cipinang Muara, keluhan mengenai pelayanan di Cengkareng Timur, keluhan mengenai pelayanan yang tidak efektif dan efisien di Jakarta Utara, dan masih banyak lagi. Data tersebut merupakan fenomena dan indikator bahwa masih ada ketidakpuasan publik di DKI Jakarta terhadap kualitas pelayanan kantor dan aparatur kelurahan.

Dari uraian dan fenomena diatas, maka penelitian perlu dilakukan terhadap persepsi masyarakat di DKI Jakarta, khususnya. Penelitian ini dilakukan dengan tujuan untuk mengetahui signifikansi pengaruh signifikan dari prosedur pelayanan, kejelasan informasi, kepastian waktu, kelengkapan sarana dan prasarana, dan kenyamanan lingkungan di kantor kelurahan secara parsial dan simultan terhadap kepuasan masyarakat.

\subsection{Persepsi}

Persepsi merupakan proses yang terintegrasi dalam diri individu terhadap stimulus yang diterimanya (Rusnani, 2013). Persepsi sebagai faktor fungsional dan faktor struktural (Rusnani, 2013). Faktor yang berperan dalam persepsi antara lain adalah objek yang dipersepsi, alat indra, syaraf, dan pusat susunan syaraf, dan perhatian. Proses terjadinya persepsi dapat dijelaskan sebagai berikut: objek menimbulkan stimulus, dan stimulus mengenai alat indra atau reseptor. Stimulus yang diterima 
oleh alat indra diteruskan oleh syaraf sensorik ke otak. Kemudian terjadilah proses diotak sebagai pusat kesadaran sehingga individu menyadari apa yang dilihat, apa yang didengar, atau apa yang diraba. Proses ini adalah proses terakhir dari persepsi dan merupakan persepsi yang sebenarnya. Respon sebagai akibat dari persepsi dapat diambil oleh individu dengan berbagai macam bentuk (Rusnani, 2013).

\subsection{Pelayanan}

Pelayanan sebagai suatu usaha untuk membantu menyampaikan (mengurus) apa yang diperlukan orang lain (Sulistiyani, Hasiolan dan Warso, 2016). Jasa merupakan suatu bentuk kegiatan yang dilakukan oleh satu orang atau lebih, umumnya sifat jasa adalah tidak berbentuk dan tidak menghasilkan kepemilikan (Tannady et al., 2017; Tanuwijaya dan Tannady, 2019). Terdapat dua faktor yang memengaruhi kualitas pelayanan yaitu pelayanan yang diharapkan (expected service) dan pelayanan yang dirasakan (perceived service) (Tjiptono, 2004). Apabila jasa yang diterima atau dirasakan (perceived service) sesuai yang diharapkan, maka kualitas jasa dipersepsikan baik dan memuaskan.

\subsection{Dimensi Pelayanan}

Terdapat lima karateristik yang digunakan oleh masyarakat dalam mengevaluasi kualitas pelayanan yaitu (Tjiptono, 2004; Tannady, Nurprihatin dan Hartono, 2018):

1. Bukti langsung (tangibles), meliputi fasilitas fisik, perlengkapan pegawai dan sarana komunikasi.

2. Kehandalan (realiability), yakni kemampuan memberikan pelayanan yang dijanjikan dengan segera dan memuaskan.

3. Daya tanggap (responsiveness), yaitu keinginan para staf untuk membantu para masyarakat dan memberikan pelayanan dengan tanggap.

4. Jaminan (assurance), yaitu mencangkup kemampuan, kesopanan dan sifat dapat dipercaya yang dimiliki para staf, bebas dari bahaya resiko atau keragu-raguan.

5. Empati (emphaty), yaitu meliputi kemudahan dalam melakukan hubungan komunikasi yang baik.

\subsection{Uji Asumsi Klasik Multikolinieritas}

Uji asumsi klasik jenis ini diterapkan untuk analisis regresi berganda yang terdiri atas dua atau lebih variabel bebas (independent variable $)\left(X_{1}, X_{2}, X_{3}, \ldots, X_{n}\right)$, dimana akan diukur tingkat asosiasi (keeratan) hubungan/pengaruh antar variabel bebas tersebut melalui besaran koefisien korelasi (r) (Sunyoto, 2009). Dikatakan terjadi multikolinieritas jika koefisien korelasi antar variabel bebas $\left(X_{1}\right.$ dan $X_{2}, X_{2}$ dan $X_{3}$, dan seterusnya) lebih besar dari 0,60 (pendapat lain: 0,50 dan 0,90). Dikatakan tidak terjadi multikolinieritas jika koefisien korelasi antar variabel bebas lebih kecil atau sama dengan $0,60 \quad(r<0,60)$. Variabel bebas mengalami multikolinieritas jika a hitung $<$ a dan VIF hitung > VIF. Variabel bebas tidak mengalami multikolinieritas jika a hitung $>$ a dan VIF hitung < VIF.

\section{Uji Asumsi Klasik Normalitas}

Uji asumsi ini akan menguji data variabel bebas $(X)$ dan data variabel terikat $(Y)$ pada persamaan regresi yang dihasilkan, apakah berdistribusi normal atau berdistribusi tidak normal (Sunyoto, 2009). Persamaan regres dikatakan baik jika mempunyai data variabel bebas dan data variabel terikat berdistribusi mendekati normal atau normal sama sekali.

\subsection{Uji Asumsi Klasik Autokorelasi}

Persamaan regresi yang baik adalah yang tidak memiliki masalah autokorelasi (Sunyoto, 2009). Jika terjadi autokorelasi, maka persamaan tersebut menjadi tidak baik atau tidak layak dipakai prediksi. Masalah autokorelasi baru timbul jika ada korelasi secara linier antara kesalahan pengangguran periode $t$ (berada) dan kesalahan pengganggu periode $t-1$ (sebelumnya).

Salah satu ukuran dalam menentukan ada tidaknya masalah autokorelasi dengan uji Durbin-Watson (DW), dengan ketentuan sebagai berikut, terjadi autokorelasi positif jika nilai DW dibawah -2 (DW < -2), tidak terjadi autokorelasi jika nilai DW berada diantara -2 dan +2 atau $-2<\mathrm{DW}<+2$, dan terjadi autokorelasi negatif jika nilai DW diatas +2 atau $\mathrm{DW}>+2$.

\section{METODOLOGI}

Penelitian diawali dengan penelitian pendahuluan, dimana penulis melakukan penelitian mengenai topik yang dibahas melalui kuesioner, wawancara dan pengamatan. Pada tahap studi pustaka, penulis mengumpulkan materi, data dan informasi dari buku, jurnal dan 
artikel yang berkaitan dengan masalah yang dibahas, serta teori-teori yang memperkuat pemahaman terhadap permasalahan. Berdasarkan penelitian pendahuluan yang dilakukan, penulis menyimpulkan masalah yang akan dianalisis dalam penulisan makalah ini. Dari masalah yang dirumuskan pada tahap sebelumnya, penulis memberikan batasan materi-materi yang akan dianalisis. Pada tahap analisis data, penulis menganalisis data-data yang diterima dari hasil pengumpulan data. Selanjutnya, penulis merumuskan kesimpulan dan saran yang diambil dari keseluruhan proses penelitian yang telah dilakukan untuk menjawab topik permasalahan yang diangkat.

\section{HASIL DAN PEMBAHASAN}

Pembahasan dimulai dengan menguji kualitas data dengan menggunakan uji validitas dan uji reliabilitas, proses pengolahan data dilakukan dengan menggunakan aplikasi SPSS. Tabel 1, Tabel 2, Tabel 3, Tabel 4 dan Tabel 5 menunjukkan bahwa corrected item-total correlation semua pernyataan yang terdapat pada variabel prosedur $>r_{\text {tabel }}$ (0.098), sehingga ketiga pernyataan tersebut dapat dinyatakan valid.

Tabel 1. Validitas Variabel Prosedur $\left(X_{I}\right)$

\begin{tabular}{ccc}
\hline Butir Pertanyaan & $\boldsymbol{r}_{\text {hitung }}$ & $\boldsymbol{r}_{\text {tabel }}$ \\
\hline $\mathbf{1}$ & 0.835 & 0.098 \\
$\mathbf{2}$ & 0.857 & 0.098 \\
$\mathbf{3}$ & 0.848 & 0.098 \\
\hline
\end{tabular}

Tabel 2. Validitas Variabel Informasi $\left(X_{2}\right)$

\begin{tabular}{ccc}
\hline Butir Pertanyaan & $\boldsymbol{r}_{\text {hitung }}$ & $\boldsymbol{r}_{\text {tabel }}$ \\
\hline $\mathbf{1}$ & 0.674 & 0.098 \\
$\mathbf{2}$ & 0.778 & 0.098 \\
$\mathbf{3}$ & 0.705 & 0.098 \\
\hline
\end{tabular}

Tabel 3. Validitas Variabel Waktu $\left(X_{3}\right)$

\begin{tabular}{ccc}
\hline Butir Pertanyaan & $\boldsymbol{r}_{\text {hitung }}$ & $\boldsymbol{r}_{\text {tabel }}$ \\
\hline $\mathbf{1}$ & 0.522 & 0.098 \\
$\mathbf{2}$ & 0.522 & 0.098 \\
\hline
\end{tabular}

Tabel 4. Validitas Variabel Sarana dan Prasarana $\left(X_{4}\right)$

\begin{tabular}{ccc}
\hline Butir Pertanyaan & $\boldsymbol{r}_{\text {hitung }}$ & $\boldsymbol{r}_{\text {tabel }}$ \\
\hline $\mathbf{1}$ & 0.762 & 0.098 \\
$\mathbf{2}$ & 0.802 & 0.098 \\
$\mathbf{3}$ & 0.794 & 0.098 \\
\hline
\end{tabular}

Tabel 5. Validitas Variabel Kenyamanan Lingkungan $\left(X_{5}\right)$

\begin{tabular}{ccc}
\hline Butir Pertanyaan & $\boldsymbol{r}_{\text {hitung }}$ & $\boldsymbol{r}_{\text {tabel }}$ \\
\hline $\mathbf{1}$ & 0.732 & 0.098 \\
$\mathbf{2}$ & 0.732 & 0.098 \\
\hline
\end{tabular}

Hasil Pengujian Reliabilitas untuk masing-masing variabel yang diringkas pada Tabel 6. berikut ini.

Tabel 6. Hasil Pengujian Reliabilitas

\begin{tabular}{lc}
\multicolumn{1}{c}{ Variabel } & Cronbach Alpha \\
\hline Prosedur & 0.924 \\
Informasi & 0.847 \\
Waktu & 0.674 \\
Sarana dan Prasarana & 0.890 \\
Kenyamanan Lingkungan & 0.843 \\
\hline
\end{tabular}

Dari Tabel 6 dilihat bahwa nilai Cronbach's Alpha untuk lima variabel independen, yakni prosedur, informasi, waktu, sarana dan prasarana serta kenyamanan lingkungan memiliki nilai cronbach's alpha > 0.6 yang berarti bahwa setiap pernyataan yang terdapat pada variabel independen ini dapat dipertanggungjawabkan dan dapat digunakan untuk proses analisis data.

\subsection{Uji Asumsi Klasik}

1. Uji Multikolinearitas

Multikolinieritas dapat dideteksi dengan nilai Variance Inflation Faktor (VIF). Hasil uji melalui VIF pada hasil output SPSS tabel Coefficients, masing masing variabel independen memiliki VIF tidak lebih dari 10 dan nilai toleransi tidak kurang dari 0.1. Maka dapat dinyatakan model regresi linier berganda terbebas dari asumsi klasik dan dapat digunakan dalam penelitian.

Tabel 7. Hasil Uji Multikolinearitas

\begin{tabular}{lcc}
\hline \multicolumn{1}{c}{ Variabel } & Tolerance & VIF \\
\hline Prosedur & 0.458 & 2.185 \\
Informasi & 0.666 & 1.501 \\
Waktu & 0.454 & 2.204 \\
Sarana dan Prasarana & 0.525 & 1.904 \\
Kenyamanan Lingkungan & 0.492 & 2.032 \\
\hline
\end{tabular}




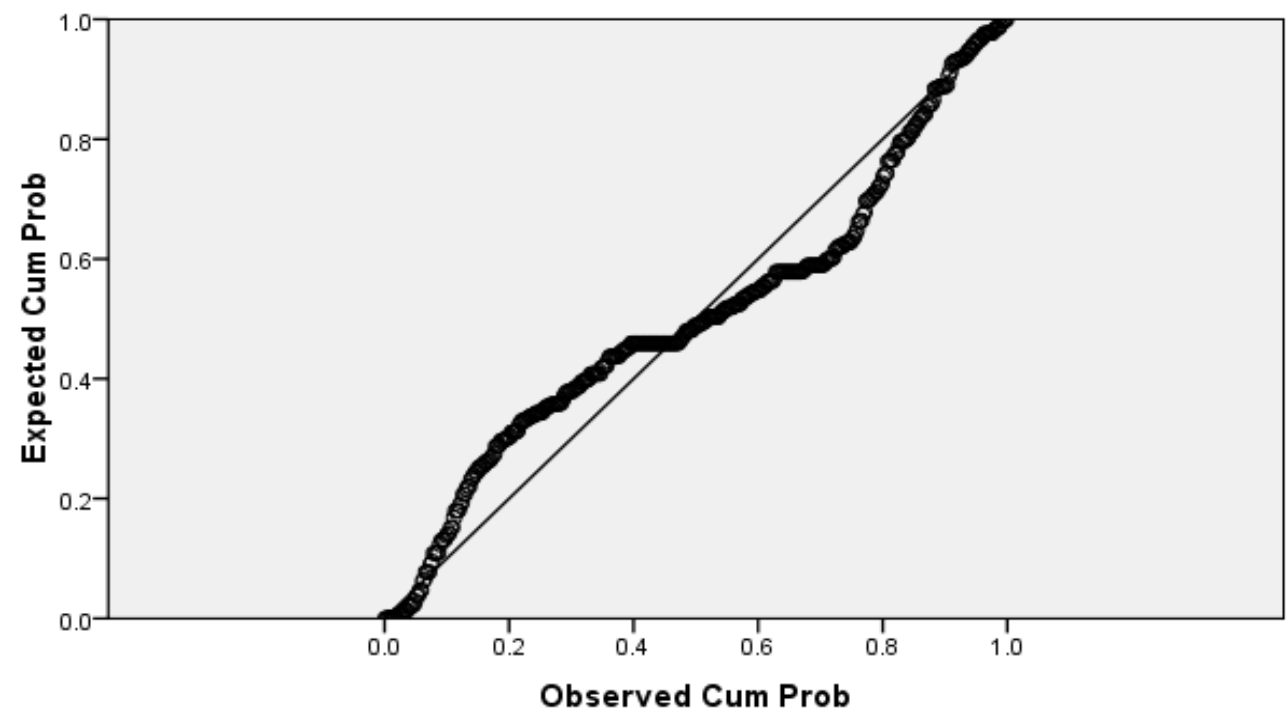

Gambar 1. Hasil Uji Normalitas

Tabel 7 menunjukkan nilai VIF dari masingmasing variabel nilainya kurang dari 10 dan seluruh nilai tolerance lebih besar dari 0.1. Maka dapat disimpulkan bahwa tidak terdapat multikolinearitas antar variabel independen dalam model regresi ini.

2. Uji Normalitas

Gambar 1 menunjukkan titik-titik tersebar dekat dengan garis diagonal yang membentang dari kiri bawah ke kanan atas. Karena titik-titik tersebut dekat dengan garis diagonal maka dapat disimpulkan bawah data tersebut terdistribusi normal atau mendekati normal. Dengan demikian, berdasarkan pengujian normalitas, model regresi layak digunakan karena memenuhi asumsi klasik.

3. Analisis Regresi Berganda

Tabel 8 menunjukkan hasil analisis regresi berganda atas 5 variabel independen terhadap 1 variabel dependen. Dengan mengacu kepada nilai dari koefisien B pada Tabel 8, maka diketahui setiap variabel independen memiliki pengaruh terhadap variabel dependen, dimana 5 variabel independen memberikan pengaruh positif. Variabel Prosedur memberikan pengaruh positif terhadap variabel Kepuasan sebesar 0.110, variabel Informasi memberikan pengaruh positif terhadap variabel Kepuasan sebesar 0.029 , variabel Waktu memberikan pengaruh positif terhadap variabel Kepuasan sebesar 0.051, variabel Sarana dan Prasarana memberikan pengaruh positif terhadap variabel Kepuasan sebesar 0.069, dan variabel Kenyamanan Lingkungan memberikan pengaruh positif terhadap variabel Kepuasan sebesar 0.176, pada hasil analisis regresi berganda terdapat nilai konstanta sebesar -0.266 .

Dari Tabel 8 dapat dibentuk persamaan regresi linear berganda untuk penelitian ini yaitu $\hat{Y}=-0.266+0.110 X_{1}+0.029 X_{2}+$ $0.051 X_{3}+0.069 X_{4}+0.176 X_{5}$, dimana $\hat{Y}$ (kepuasan), $X_{1}$ (prosedur), $X_{2}$ (informasi), $X_{3}$ (waktu), $X_{4}$ (sarana dan prasarana) dan $X_{5}$ (kenyamanan lingkungan). 
Tabel 8. Hasil Analisis Regresi Berganda

Coefficients $^{a}$

\begin{tabular}{|c|c|c|c|c|c|c|}
\hline \multirow{2}{*}{\multicolumn{2}{|c|}{ Model }} & \multicolumn{2}{|c|}{ Unstandardized Coefficients } & \multirow{2}{*}{$\begin{array}{c}\begin{array}{c}\text { Standardized } \\
\text { Coefficients }\end{array} \\
\text { Beta } \\
\end{array}$} & \multirow[b]{2}{*}{$t$} & \multirow[b]{2}{*}{ Sig. } \\
\hline & & $\mathrm{B}$ & Std. Error & & & \\
\hline \multirow[t]{6}{*}{1} & (Constant) & -.266 & .143 & & -1.862 & .063 \\
\hline & Total Prosedur & .110 & .015 & .322 & 7.465 & .000 \\
\hline & Total Informasi & .029 & .012 & .089 & 2.504 & .013 \\
\hline & Total Waktu & .051 & .023 & .097 & 2.250 & .025 \\
\hline & Total Sarana & .069 & .016 & .180 & 4.465 & .000 \\
\hline & Total Lingkungan & .176 & .023 & .317 & 7.629 & .000 \\
\hline
\end{tabular}

a. Dependent Variable: KPS

Tabel 9. Hasil Analisis Uji f

ANOVA $^{\text {b }}$

\begin{tabular}{|ll|r|r|r|r|r|}
\hline \multicolumn{2}{|c|}{} & \multicolumn{1}{c|}{$\begin{array}{c}\text { Sum of } \\
\text { Squares }\end{array}$} & \multicolumn{1}{c|}{$\mathrm{df}$} & Mean Square & \multicolumn{1}{c|}{$\mathrm{F}$} & Sig. \\
\hline 1 & Regression & 223.121 & 5 & 44.624 & 156.537 & $.000^{\mathrm{a}}$ \\
& Residual & 112.319 & 394 & .285 & & \\
& Total & 335.440 & 399 & & & \\
\hline
\end{tabular}

a. Predictors: (Constant), Total Lingkungan, Total Informasi, Total Waktu, Total Sarana, Total Proseduı

b. Dependent Variable: KPS

Kesimpulan dari hipotesis pertama yang menyatakan bahwa terdapat pengaruh yang signifikan dari variabel prosedur terhadap kepuasan, berdasarkan nilai signifikansi yaitu $0.000<$ dari 0.05 disimpulkan bahwa $\mathrm{H}_{0}$ ditolak, artinya terdapat pengaruh yang signifikan dari variabel prosedur terhadap kepuasan. Kesimpulan dari hipotesis kedua yang menyatakan bahwa terdapat pengaruh yang signifikan dari variabel informasi terhadap kepuasan, berdasarkan nilai signifikansi yaitu $0.013<$ dari 0.05 disimpulkan bahwa $H_{0}$ ditolak, artinya terdapat pengaruh yang signifikan dari variabel informasi terhadap kepuasan. Kesimpulan dari hipotesis ketiga yang menyatakan bahwa terdapat pengaruh yang signifikan dari variabel waktu terhadap kepuasan, berdasarkan nilai signifikansi yaitu $0.025<$ dari 0.05 disimpulkan bahwa $H_{0}$ ditolak, artinya terdapat pengaruh yang signifikan dari variabel waktu terhadap kepuasan. Kesimpulan dari hipotesis keempat yang menyatakan bahwa terdapat pengaruh yang signifikan dari variabel sarana dan prasarana terhadap kepuasan, berdasarkan nilai signifikansi yaitu $0.000<$ dari 0.05 disimpulkan bahwa $H_{0}$ ditolak, artinya terdapat pengaruh yang siginifikan dari variabel sarana dan prasarana terhadap kepuasan. Kesimpulan dari hipotesis kelima yang menyatakan bahwa terdapat pengaruh yang signifikan dari variabel kenyamanan lingkungan terhadap kepuasan, berdasarkan nilai signifikansi yaitu $0.000<$ dari 0.05 disimpulkan bahwa $H_{0}$ ditolak, artinya terdapat pengaruh yang siginifikan dari variabel kenyamanan lingkungan terhadap kepuasan.

Berdasarkan tabel hasil uji otokorelasi, dapat dilihat bahwa nilai koefisien untuk uji pengaruh secara bersama-sama atau parsial adalah sebesar 0.665 , artinya secara bersamasama prosedur, informasi, waktu, sarana dan prasarana serta kenyamanan lingkungan memberikan pengaruh sebesar 0.665 atau $66.5 \%$ terhadap kepuasan warga DKI Jakarta terhadap pelayanan kantor kelurahan. Nilai signifikansi berdasarkan Tabel 9, yaitu 0.000 $<$ dari $0.05 . H_{0}$ ditolak, artinya terdapat pengaruh yang signifikan dari variabel prosedur, informasi, waktu, sarana dan prasarana, dan kenyamanan lingkungan secara bersama-sama terhadap kepuasan. 


\section{SIMPULAN}

Prosedur, informasi, waktu, sarana dan prasarana, dan kenyamanan lingkungan berpengaruh positif dan signifikan terhadap kepuasan warga DKI Jakarta kepada pelayanan kantor kelurahan dengan nilai koefisien estimasi masing-masing sebesar $0.110 ; 0.029 ; 0.051$; $0.069 ; 0.176$ dan nilai t masing-masing sebesar $0.000 ; 0.013 ; 0.025 ; 0.000 ; 0.000$. Prosedur, informasi, waktu, sarana dan prasarana, serta kenyamanan lingkungan secara bersama-sama berpengaruh positif dan signifikan terhadap kepuasan warga DKI Jakarta kepada pelayanan kantor kelurahan dengan nilai koefisien 0.665 $(66.5 \%)$, sementara sisanya $33.5 \%$ disebabkan oleh faktor lain yang tidak dibahas pada penelitian ini.

Saran bagi pemerintah provinsi DKI Jakarta tetap mempertahankan dan meningkatkan prosedur pelayanan yang telah ada, beberapa atribut informasi yang sudah sangat baik, nilai-nilai yang baik mengenai kepastian waktu penyelesaian pelayanan, beberapa aspek sarana dan prasarana (seperti perlengkapan kerja, perangkat teknologi informasi), dan kondisi lingkungan yang nyaman, baik itu di kantor pelayanan ataupun di fasilitas penunjang pelayanan (seperti musholla, tempat parkir, toilet, dan ruang tunggu). Saran bagi peneliti selanjutnya adalah untuk mengembangkan keilmuan, khususnya terkait dengan bagaimana mengukur kepuasan masyarakat terhadap pemerintah provinsi dengan menggunakan parameter pelayanan di kantor kelurahan, sebaiknya dikembangkan penelitian dengan menggunakan variabel independen lain atau memperkaya indikator yang telah digunakan pada penelitian ini. Saran bagi penelitian selanjutnya adalah dapat mengimplementasikan service quality pada berbagai macam industri, seperti makanan ceat saji (Lestari, Tannady dan Nurprihatin, 2018), maskapai penerbangan (Tannady et al., 2017), dan pasar tradisional (Soetopo, Tannady dan Nurprihatin, 2017).

\section{DAFTAR PUSTAKA}

Chatzoglou, P. et al. (2013) "Service quality in the public sector: The case of the Citizen's Service Centers (CSCs) of Greece," International Journal of Productivity and Performance Management, 62(6), hal. 583-605. doi: 10.1108/IJPPM-12-20120140 .
Lestari, A., Tannady, H. dan Nurprihatin, F. (2018) "Analisis Produktivitas Kasir Guna Menentukan Beban Kerja Menggunakan Work Sampling pada Gerai Makanan Cepat Saji," in Prosiding Seminar Rekayasa Teknologi. Jakarta: Fakultas Teknik Universitas Pancasila, hal. 578-587.

Ningsih, A. A. (2015) "Kinerja Aparatur dalam Meningkatkan Pelayanan Publik pada Kantor Kelurahan Nunukan Tengah Kabupaten Nunukan," eJournal Ilmu Administrasi Negara, 3(4), hal. 12951306.

Papadomichelaki, X. dan Mentzas, G. (2011) "Analysing E-government Service Quality in Greece," Electronic Government, 8(4), hal. 290-308. doi: 10.1504/EG.2011.042808.

Rahayu, M., Rasid, F. dan Tannady, H. (2018) "Effects of Self Efficacy, Job Satisfaction, and Work Culture Toward Performance of Telemarketing Staff in Banking Sector," South East Asia Journal of Contemporary Business, Economics and Law, 16(5), hal. 47-52.

Rahayu, M., Rasid, F. dan Tannady, H. (2019) "The Effect of Career Training and Development on Job Satisfaction and its Implications for the Organizational Commitment of Regional Secretariat (SETDA) Employees of Jambi Provincial Government," International Review of Management and Marketing, 9(1), hal. 79-89.

Ramseook-Munhurrun, P., Lukea-Bhiwajee, S. D. dan Naidoo, P. (2010) "Service Quality in Public Service," International Journal of Management and Marketing Research, 3(1), hal. 37-50.

Rusnani, S. (2013) "Persepsi Masyarakat tentang Pelayanan Publik di Kantor Kelurahan Handil Bakti Kecamatan Palaran Kota Samarinda," eJournal Administrasi Negara, 1(2), hal. 365-379.

Sancoko, B. (2010) "Pengaruh Remunerasi terhadap Kualitas Pelayanan Publik," Bisnis dan Birokrasi: Jurnal Ilmu Administrasi dan Organisasi, 17(1), hal. 43-51. doi: 10.20476/jbb.v17i1.625.

Soetopo, H. S. R., Tannady, H. dan Nurprihatin, F. (2017) "Perancangan Ulang Tata Letak Pasar Johar Baru untuk Mengurangi Kepadatan Lalu Lintas dalam Pasar," 
Journal of Industrial Engineering and Management Systems, 10(1), hal. 12-24.

Sulistiyani, Hasiolan, L. B. dan Warso, M. M. (2016) "Analisis Pengaruh Indeks Kepuasan Masyarakat terhadap Pelayanan Publik di Kelurahan Pudakpayung Kecamatan Banyumanik Kota Semarang," Journal of Management, 2(2), hal. 1-25.

Sunyoto (2009) Analisis Regresi dan Uji Hipotesis. Yogyakarta: Media Pressindo.

Tannady, H. et al. (2017) “Analisis Kualitas Jasa pada Maskapai Penerbangan Rute Domestik Tarif Menengah Kebawah dengan Menggunakan Metode Servqual dan Metode Importance and Performance Analysis," in Prosiding Seminar Nasional Teknologi dan Informatika. Kudus: Fakultas Teknik Universitas Muria Kudus, hal. 523-529.

Tannady, H., Erlyana, Y. dan Nurprihatin, F. (2019) "Effects of work environment and self-efficacy toward motivation of workers in creative sector in province of Jakarta, Indonesia," Quality - Access to Success, 20(172), hal. 165-168.

Tannady, H., Ismuhadjar, H. dan Zami, A. (2019) "The Effect of Organizational Culture and Employee Engagement on Job Performance of Healthcare Industry in Province of Jakarta, Indonesia,"
Quality: Access to Success, 20(169), hal. 18-22.

Tannady, H., Nurprihatin, F. dan Hartono, H. (2018) "Service quality analysis of two of the largest retail chains with minimart concept in Indonesia," Business: Theory and Practice, 19, hal. 177-185. doi: 10.3846/BTP.2018.18.

Tannady, H. dan Sitorus, T. (2017) "Role of Compensation, Organization Culture, and Leadership on Working Motivation of Faculty Member (Study Case: Universities in North Jakarta)," IOSR Journal of Business and Management, 19(10), hal. 41-47. doi: 10.9790/487X1910034147.

Tanuwijaya, C. dan Tannady, H. (2019) "Evaluasi Produk dan Pelayanan di Toko Buku Gramedia Emporium Pluit Mall Jakarta Utara Menggunakan Service Quality," in Prosiding Seminar Nasional Sains dan Teknologi Informasi. Medan: STMIK Budi Darma, hal. 25-28.

Tjiptono, F. (2004) Manajemen Jasa. Yogyakarta: Andi.

Yandri, P. (2013) "Kepuasan Masyarakat terhadap Pelayanan Kelurahan setelah Pemekaran di Tangerang Selatan," Journal Liquidity, 2(2), hal. 151-159. 